\title{
A new series of the SMTP plasminogen modulator with a phenylglycine-based side chain
}

\author{
Haruki Koide, Ritsuko Narasaki, Keiko Hasegawa, Naoko Nishimura and Keiji Hasumi
}

The Journal of Antibiotics (2012) 65, 91-93; doi:10.1038/ja.2011.108; published online 23 November 2011

Keywords: fibrinolysis; plasminogen modulator; proteolysis; structure-activity relationships

The plasminogen/plasmin system has a central role in blood clot lysis. ${ }^{1}$ The system is also important in other pathophysiological events, where localized proteolysis is involved. ${ }^{2}$ Plasminogen is proteolytically activated to plasmin by plasminogen activators through specific cleavage at $\mathrm{Arg}^{561}-\mathrm{Val}^{562}{ }^{1}$ Plasminogen adopts tight conformation due to intramolecular binding of Lys ${ }^{50}$ and/or Lys ${ }^{62}$ to the lysinebinding site in the fifth kringle domain. ${ }^{3,4}$ The tight conformation renders plasminogen less sensitive to activation by plasminogen activators. Plasminogen binding to fibrin or cellular receptors allows relaxation of plasminogen conformation, enabling efficient activation. This mechanism facilitates localized activation of plasminogen and following extracellular proteolysis. ${ }^{5}$

Stachybotrys microspora triprenyl phenols (SMTPs) are triprenyl phenol metabolites from the fungus Stachybotrys microspora. ${ }^{5}$ SMTP enhances both activation and fibrin binding of plasminogen by modulating plasminogen conformation. ${ }^{5-7}$ SMTP-7, one of the most potent congeners, is effective in treating thrombotic stroke. ${ }^{8-11}$ The SMTP molecule consists of a tricyclic $\gamma$-lactam moiety, a geranylmethyl group, and an $N$-linked side chain. Our previous studies identified 26 SMTP congeners, most of which differ in the side chain. ${ }^{12-18}$ Plasminogen modulator activities of the congeners differ depending on the $\mathrm{N}$-linked side-chain structure. It has been suggested that a negatively ionizable group in the $N$-linked side chain is crucial for activity. ${ }^{18}$ Among congeners with a negatively chargeable side chain, one with an aromatic group as the side chain is more active than that with an aliphatic group. ${ }^{18}$ In this study, we isolated five new SMTP congeners with a phenylglycine-based side chain to investigate structure-activity relationships further. This paper deals with the isolation and characterization of these congeners. Part of the results has been disclosed as a patent. ${ }^{19}$ Biological activities of some of the new congeners have also been described in patent literatures. ${ }^{20,21}$

Our previous studies established fermentation conditions that enable efficient selective production of an SMTP congener through feeding of a precursor amine to $S$. microspora cultures. ${ }^{17,22}$ Based on this method, we produced five new SMTP congeners with a phenyl- glycine-based $N$-linked side chain (Supplementary Materials and Methods). Precursor amines fed for the production is shown in Supplementary Table S1. A culture fed with an optically active precursor afforded single major product (SMTP-43, -43D, -44, or $-44 \mathrm{D}$ ), whereas a culture fed with racemic 3-hydroxy-D,L-phenylglycine gave two major products, which were separable each other on reversed-phase HPLC (retention times at 11.5 and 13.3 min under conditions described in Supplementary Table S1). The slow-eluting isomer was successfully purified on preparative HPLC, whereas the fast-eluting isomer could not be obtained as a homogenous state. The yield varied among the five congeners, ranging from 94 to $1351 \mathrm{mg} \mathrm{l}^{-1}$ (Supplementary Table S1).

Physicochemical properties of the new congeners are summarized in Table 1 (see Supplementary Materials and Methods for detailed conditions for the analyses). NMR signals (Supplementary Figures S1S5) are assigned as shown in Supplementary Table S2 according to the results from ${ }^{1} \mathrm{H}-{ }^{1} \mathrm{H}$-correlation, heteronuclear multiple quantum coherence and heteronuclear multiple-bond connectivity spectroscopies. Based on these results, we propose the structures of the new congeners as shown in Figure 1a. The conclusion is consistent with the idea that the fed amine is introduced as the $N$-linked side chain of an SMTP molecule. ${ }^{16,17,22}$ The stereochemistry of SMTP-45D, the sloweluting isomer produced in a culture fed with the racemic precursor, was proposed based on the following facts: (i) the $26 R$ epimers, SMTP-43D and $-44 \mathrm{D}$, were eluted slower on reversed-phase HPLC compared with respective $26 S$ epimers, SMTP-43 and -44 (Supplementary Table S1); (ii) specific optical rotations of SMTP-43 and -44 were in the plus sign, while those of SMTP-43D and -44D were in the minus sign (Table 1); (iii) retention time of SMTP-45D was slower than the its epimer ( $13.3 \mathrm{~min}$ compared with $11.5 \mathrm{~min}$ ), and specific rotation of SMTP-45D was in the minus sign (Table 1); (iv) S. microspora culture fed with 3-hydroxy-L-phenylglycine ((S)-3hydroxyphenylglycine) afforded the fast-eluting epimer but not the slow-eluting one (Supplementary Figure S6). Therefore, $R$ configuration was assigned to position 26 in SMTP-45D. 
Table 1. Physicochemical properties of new SMTP congeners

\begin{tabular}{|c|c|c|c|c|c|}
\hline & SMTP-43 & $S M T P-43 D$ & SMTP-44 & $S M T P-44 D$ & SMTP-45D \\
\hline \multicolumn{6}{|l|}{ MALDI-TOF-MS } \\
\hline Found $(\mathrm{M}+\mathrm{H})^{+}$: & 520.2662 & 520.2662 & 536.2656 & 536.2671 & 536.2723 \\
\hline Calculated: & $\begin{array}{c}520.2699 \text { for } \\
\mathrm{C}_{31} \mathrm{H}_{38} \mathrm{NO}_{6}\end{array}$ & $\begin{array}{c}520.2699 \text { for } \\
\mathrm{C}_{31} \mathrm{H}_{38} \mathrm{NO}_{6}\end{array}$ & $\begin{array}{c}536.2648 \text { for } \\
\mathrm{C}_{31} \mathrm{H}_{38} \mathrm{NO}_{7}\end{array}$ & $\begin{array}{c}536.2648 \text { for } \\
\mathrm{C}_{31} \mathrm{H}_{38} \mathrm{NO}_{7}\end{array}$ & $\begin{array}{c}536.2648 \text { for } \\
\mathrm{C}_{31} \mathrm{H}_{38} \mathrm{NO}_{7}\end{array}$ \\
\hline & $259\left(\begin{array}{lll}11 & 112\end{array}\right)$ & $259(11008)$ & $262(11026)$ & $261(11730)$ & $261(13703)$ \\
\hline & 300 (3 012) & 300 (3 012) & 300 (2 783) & 300 (2946) & 300 (3 747) \\
\hline IR $v_{\max }$ (neat) $\mathrm{cm}^{-1}$ & $\begin{array}{l}3423,2968,2920 \\
2864,1726,1660 \\
1620,1464,1350 \\
1205,1169,1074\end{array}$ & $\begin{array}{l}3354,2968,2922, \\
2862,1714,1664, \\
1620,1466,1356, \\
1207,1167,1074\end{array}$ & $\begin{array}{c}3348,2974,2922,2856 \\
1718,1660,1612,1514 \\
1464,1365,1211,1173 \\
1072,922,827,768\end{array}$ & $\begin{array}{c}3325,2970,2922,2858 \\
1711,1662,1612,1512 \\
1464,1365,1217,1173, \\
1074,922,831,771\end{array}$ & $\begin{array}{l}3309,2974,2924,2864, \\
1707,1662,1603,1464, \\
1365,1224,1163,1076, \\
847,771,712,656,536\end{array}$ \\
\hline
\end{tabular}

Abbreviation: SMTP, Stachybotrys microspora triprenyl phenol.

a<smiles>CC(C)=CCCC(C)=CC[C@@]1(C)Oc2c(c(O)cc3c2CN(P)C3=O)C[C@H]1O</smiles>

Compound

SMTP-43D

SMTP-43<smiles>CC(C(=O)O)c1ccccc1</smiles><smiles>CC(C(=O)O)c1ccc(O)cc1</smiles>

SMTP-44D<smiles>C[C@@H](C(=O)O)c1ccccc1</smiles><smiles>CC(C(=O)O)c1ccc(O)cc1</smiles>

SMTP-45D<smiles>CC(C(=O)O)c1cccc(O)c1</smiles>

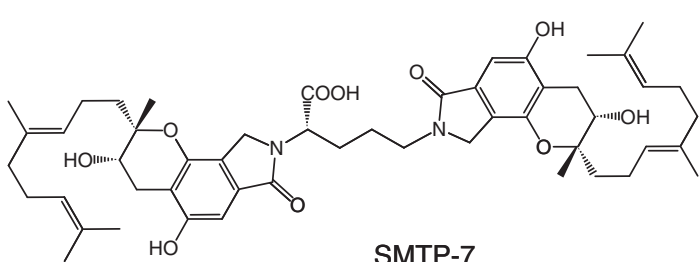

SMTP-7

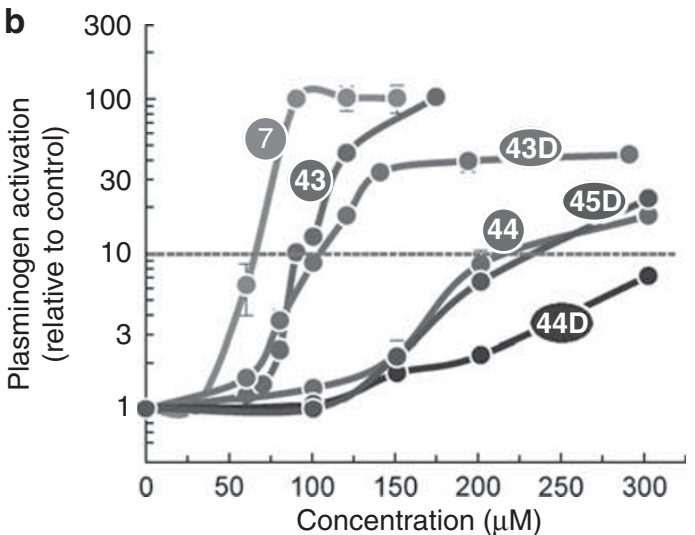

c

\begin{tabular}{|c|c|c|c|}
\hline Compound & $\begin{array}{l}E C_{10} \\
(\mu \mathrm{M})\end{array}$ & $\begin{array}{l}E_{\max } \\
\text { (fold) }\end{array}$ & $\begin{array}{c}\text { Potency } \\
\left(E_{\max x} / \mathrm{EC}_{10}\right)\end{array}$ \\
\hline SMTP-7 & 65 & 102 & \\
\hline SMTP-43 & 89 & 103 & \\
\hline SMTP-43D & 103 & 44 & \\
\hline SMTP-44 & 210 & 18 & \\
\hline SMTP-44D & NA & 7 & \\
\hline SMTP-45D & 230 & 23 & \\
\hline
\end{tabular}

Figure 1 Structure and activity of new SMTP congeners. (a) Structures of new SMTP congeners and SMTP-7. (b) The activation of plasminogen was assayed in the presence of the indicated concentrations of each SMTP congener. Numbers in circle represent the SMTP number. Each value represents the mean \pm s.d. from triplicate determinations. Percent of control values are shown. (c) Summary of the results in panel b. EC 10 , concentration ( $\mu \mathrm{m}$ ) of SMTP that causes 10-fold enhancement of plasminogen activation; $E_{\max }$, maximum level of enhancement (fold increase in plasminogen activation compared with control). $E_{\max }$ and the reciprocal of $\mathrm{EC}_{10}$ are independent indexes that represent the potency of the compound. The ratio $E_{\max } / \mathrm{EC}_{10}$ represents comprehensive potency. $\mathrm{NA}$, not available (due to that enhancement did not reach 10 -fold at concentrations tested). A full color version of this figure is available at The Journal of Antibiotics journal online.

Plasminogen modulator activities of the five new SMTP congeners (Figures $1 \mathrm{~b}$ and $\mathrm{c}$ ) were assessed as their activity to enhance plasminogen activation (see Supplementary Materials and Methods) in comparison with SMTP-7, one of the most potent congeners identified so far. SMTP-43, which had an L-2-phenylglycine moiety as the $N$-linked side chain, was potent in enhancing plasminogen activation. The concentration that caused 10 -fold enhancement $\left(\mathrm{EC}_{10}\right)$ was $89 \mu \mathrm{M}$, and the maximum level of the enhancement $\left(E_{\max }\right)$ 
exceeded 100 -fold (Figures $1 \mathrm{~b}$ and c). These parameters were comparable to those of SMTP-7 $\left(\mathrm{EC}_{10}=65 \mu \mathrm{M} ; E_{\max }=102\right.$-fold). The $26 R$ epimer SMTP-43D $\left(E_{\max } / \mathrm{EC}_{10}=0.43\right.$-fold $\left.\mu_{\mathrm{M}}^{-1}\right)$, which had a D-2phenylglycine moiety, was significantly weaker than SMTP-43 $\left(E_{\max } /\right.$ $\mathrm{EC}_{10}=1.16$-fold $\left.\mu \mathrm{M}^{-1}\right)$. SMTP-44, an analog of SMTP-43 with a hydroxyl group at position 30, was $\sim 13$ times less active than SMTP-43 in terms of the $E_{\max } / \mathrm{EC}_{10}$ value (Figures $1 \mathrm{~b}$ and $\mathrm{c}$ ). SMTP-44D was much less active than its epimer, SMTP-44, giving sevenfold enhancement even at $300 \mu \mathrm{M}$. The potency $\left(E_{\max } / E_{10}\right)$ of SMTP-45D was $\sim 1 / 4$ of that of SMTP-43D, while SMTP-45D was significantly more active than the regioisomer SMTP-44D.

Thus, among the series of SMTP congeners with a phenylglycinebased side chain, SMTP-43, which has no hydroxyl group in the side chain, is most potent. Its activity is comparable to the two-unit congener SMTP-7, which has two triprenyl phenol units. The introduction of a phenolic hydroxyl group into the $N$-linked side chain of SMTP-43 results in a decrease in potency. The position of the hydroxyl group affects the potency of a congener. A congener with an $S$ configuration at the phenylglycine moiety is more active than that with an $R$ configuration.

\section{ACKNOWLEDGEMENTS}

Human plasma for plasminogen isolation was provided by the Japanese Red Cross Society, Tachikawa. This work was supported in part by grant from the Japan Society for the Promotion of Science.

1 Rijken, D. C. \& Lijnen, H. R. New insights into the molecular mechanisms of the fibrinolytic system. J. Thromb. Haemost. 7, 4-13 (2008).

2 Castellino, F. J. \& Ploplis, V. A. Structure and function of the plasminogen/plasmin system. Thromb. Haemost. 93, 647-654 (2005).

3 Cockell, C. S., Marshall, J. M., Dawson, K. M., Cederholm-Williams, S. A. \& Ponting, C. P. Evidence that the conformation of unliganded human plasminogen is maintained via an intramolecular interaction between the lysine-binding site of kringle 5 and the $\mathrm{N}$ terminal peptide. Biochem. J. 333, 99-105 (1998).

4 An, S. S. et al. Lysine-50 is a likely site for anchoring the plasminogen N-terminal peptide to lysine-binding kringles. Protein Sci. 7, 1960-1969 (1998).

5 Hasumi, K., Yamamichi, S. \& Harada, T. Small molecule modulators of the zymogen activation in the fibrinolytic and coagulation systems. FEBS J. 277, 3675-3687 (2010)
6 Takayasu, R., Hasumi, K., Shinohara, C. \& Endo, A. Enhancement of fibrin binding and activation of plasminogen by staplabin through induction of a conformational change in plasminogen. FEBS Lett. 418, 58-62 (1997).

7 Ohyama, S., Harada, T., Chikanishi, T., Miura, Y. \& Hasumi, K. Nonlysine-analog plasminogen modulators promote autocatalytic generation of plasmin(ogen) fragments with angiostatin-like activity. Eur. J. Biochem. 271, 809-820 (2004).

8 Hashimoto, T., Shibata, K., Nobe, K., Hasumi, K. \& Honda, K. A novel embolic model of cerebral infarction and evaluation of SMTP-7, a novel fungal triprenyl phenol metabolite. J. Pharmacol. Sci. 114, 41-49 (2010).

9 Shibata, K. Hashimoto, T., Nobe, K, Hasumi, K. \& Honda, K. A novel finding of a lowmolecular-weight compound, SMTP-7, having thrombolytic and anti-inflammatory effects in cerebral infarction of mice. N.-S. Arch. Pharmacol. 382, 245-253 (2010).

10 Miyazaki, T. et al. Distinct effects of tissue-type plasminogen activator and SMTP-7 on cerebrovascular inflammation following thrombolytic reperfusion. Stroke $\mathbf{4 2}$, 1097-1104 (2011).

11 Shibata, K., Hashimoto, T., Nobe, K., Hasumi, K. \& Honda, K. Neuroprotective mechanisms of SMTP-7 in cerebral infarction model in mice. N.-S. Arch. Pharmacol. 384, 103-108 (2011).

12 Shinohara, C., Hasumi, K., Hatsumi, W. \& Endo, A. Staplabin, a novel fungal triprenyl phenol which stimulates the binding of plasminogen to fibrin and U937 cells. J. Antibiot. 49, 961-966 (1996).

13 Kohyama, T., Hasumi, K., Hamanaka, A. \& Endo, A. SMTP-1 and -2, novel analogs of staplabin produced by Stachybotrys microspora IF030018. J. Antibiot. 50, 172-174 (1997).

14 Hasumi, K. et al. Isolation of SMTP-3, $-4,-5$ and -6 , novel analogs of staplabin, and their effects on plasminogen activation and fibrinolysis. J. Antibiot. 51, 1059-1068 (1998).

$15 \mathrm{Hu}$, W., Ohyama, S. \& Hasumi, K. Activation of fibrinolysis by SMTP-7 and -8 , novel staplabin analogs with a pseudosymmetric structure. J. Antibiot. 53, 241-247 (2000).

$16 \mathrm{Hu}$, W., Kitano, Y. \& Hasumi, K. SMTP-4D, -5D, -6D, -7D and -8D, a new series of the non-lysine-analog plasminogen modulators with a D-amino acid moiety. J. Antibiot. 56, 832-837 (2003).

17 Hasumi, K., Hasegawa, K. \& Kitano, Y. Isolation and absolute configuration of SMTP-O, a simplest congener of the SMTP family nonlysine-analog plasminogen modulators. J. Antibiot. 60, 463-468 (2007).

18 Hasegawa, K. et al. Structure-activity relationships of fourteen new congeners of the SMTP plasminogen modulator. J. Antibiot. 63, 589-593 (2010).

19 Hasumi, K. et al. Triprenyl phenol compound, process for production of triprenyl phenol compound, and thrombolysis enhancer, Tokyo University of Agriculture and Technology TLO Co., Ltd., PCT/JP2007/055749, 20 March (2007).

20 Hasumi, K., Ishikawa, M., Chikanishi, T., Nishimura, N. \& Hasegawa, K. Pharmacological composition for metabolic syndrome, obesity, hyperglycemia, hyperlipidemia and/ or fatty liver, Tokyo University of Agriculture and Technology, PCT/JP2010/053545, 4 March (2010).

21 Honda, K., Hashimoto, T., Shibata, K., Hasegawa, K. \& Hasumi, K. Cytoprotective agent, Tokyo University of Agriculture and Technology, Showa University, TMS Co., Ltd., PCT/JP2010/051711, 5 February (2010).

$22 \mathrm{Hu}$, W., Ohyama, S., Narasaki, R. \& Hasumi, K. Selective production of staplabin and SMTPs in cultures of Stachybotrysmicrospora fed with precursor amines. J. Antibiot. 54, 962-966 (2001).

Supplementary Information accompanies the paper on The Journal of Antibiotics website (http://www.nature.com/ja) 